\title{
Working
}

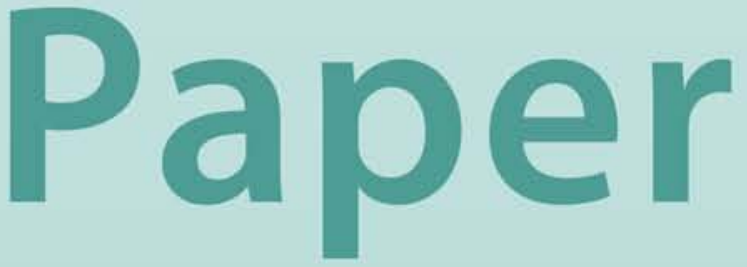


Monetary Policy and the Lost Decade:

Lessons from Japan

Daniel Leigh 


\title{
IMF Working Paper
}

Research Department

\section{Monetary Policy and the Lost Decade: Lessons from Japan}

\section{Prepared by Daniel Leigh ${ }^{1}$}

Authorized for distribution by Jörg Decressin

October 2009

\begin{abstract}
This Working Paper should not be reported as representing the views of the IMF.

The views expressed in this Working Paper are those of the author(s) and do not necessarily represent those of the IMF or IMF policy. Working Papers describe research in progress by the author(s) and are published to elicit comments and to further debate.

This paper investigates how monetary policy can help ward off a protracted deflationary slump when policy rates are near the zero bound by studying the experience of Japan during the "Lost Decade" which followed the asset-price bubble collapse in the early 1990s. Estimation results based on a structural model suggest that the Bank of Japan's interest-rate policy fits a conventional forward-looking reaction function with an inflation target of about 1 percent. The disappointing economic performance thus seems primarily due to a series of adverse economic shocks rather than an extraordinary policy error. In addition, counterfactual policy simulations based on the estimated structural model suggest that simply raising the inflation target would not have yielded a lasting improvement in performance. However, a price-targeting rule or a policy rule that combined a higher inflation target with a more aggressive response to output would have achieved superior stabilization results.
\end{abstract}

JEL Classification Numbers:C22, E31, E52

Keywords: liquidity trap, deflation, monetary policy, Bayesian econometrics

Author’s E-Mail Address: dleigh@imf.org

\footnotetext{
${ }^{1}$ I am especially grateful to Laurence Ball, Athanasios Orphanides, Alan Auerbach, and Pau Rabanal for helpful comments. I also thank participants at seminars hosted by the IMF Research Department and the NBER's Working Group on Japan. Yasuo Hirose kindly providing me with the data.
} 


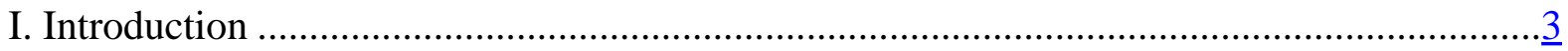

II. Empirical Analysis ........................................................................................................

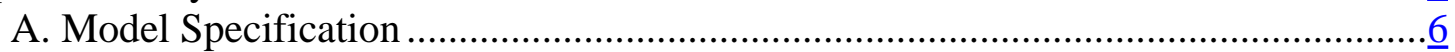

B. Model Estimation …………………………………….....................................

III. Counterfactual Analysis...................................................................................................

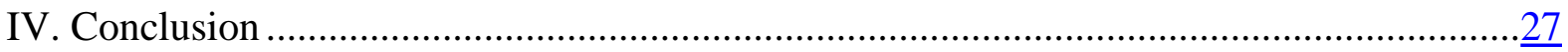

Tables

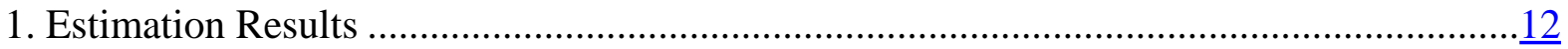

2. Actual and Counterfactual Inflation and Output Loss .....................................................20

Figures

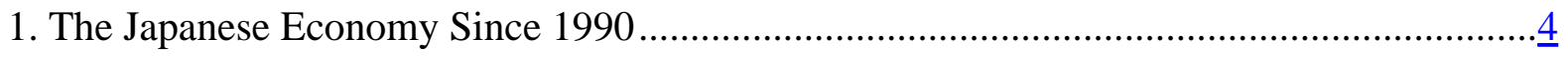

2. Estimation Results: Implicit Inflation Target …………................................................13

3. Estimation Results: Natural Rate of Interest...................................................................14

4. Estimated Policy-Rate Target and Actual Policy Rate ………........................................... 15

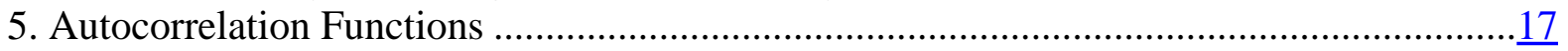

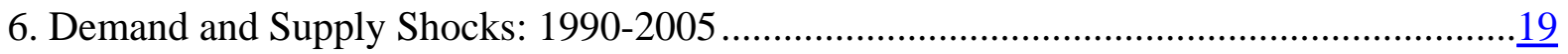

7. Actual and Counterfactual Macroeconomic Dynamics:......................................................21

8. Actual and Counterfactual Macroeconomic Dynamics: ......................................................22

9. Actual and Counterfactual Macroeconomic Dynamics:........................................................24

10. Actual and Counterfactual Macroeconomic Dynamics: ......................................................26

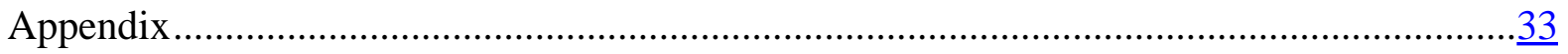

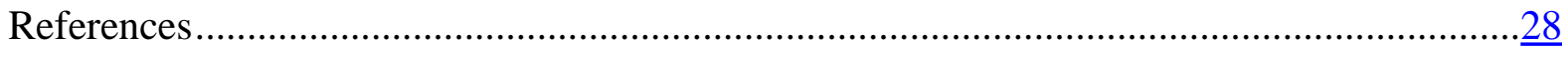




\section{INTRODUCTION}

The prospect of advanced economies remaining in a deep slump with deflation and policy interest rates constrained by the zero bound has stimulated research into how monetary policy can respond to such risks. ${ }^{2}$ This paper seeks to shed light on the topic by focusing on the experience of Japan, a country that entered a liquidity trap in the mid-1990s, and experienced a "Lost Decade” (Hiyashi and Prescott, 2002) of slow growth, deflation, and output persistently below potential (Figure 1). ${ }^{3}$ Japan's experience has stimulated a lively debate about what went wrong. As Blanchard (2000) notes "this may not be a bad time to assess the lessons from the Japanese full experiment” (Blanchard, 2000, p. 185). A number of authors attribute much of the economy's disapointing performance to "exceptionally poor monetary policymaking” (Bernanke, 2000, p. 150). In addition, Kuttner and Posen (2002) find that "Japanese fiscal policy was contractionary over much of the 1990s," and attribute part of the protracted downturn to insufficient fiscal stimulus. However, this paper focuses on the contribution of monetary policy.

What policy was the Bank of Japan following, what “exceptional mistakes” did it make, and what, if anything, could it have done to help avoid the "Lost Decade?” This paper addresses these questions by first investigating whether the Bank of Japan's interest-rate policy is well described by a standard Taylor-type monetary policy reaction function. The empirical analysis is based on a stylized structural model of the Japanese economy with the innovation that the implicit inflation target, and the natural rate of interest- two important parameters for assessing the stance of monetary policy_are allowed to vary over time. Secondly, the paper conducts counterfactual simulations based on the estimated structural model to investigate whether alternative interest-rate policy approaches proposed in the literature could have improved macroeconomic performance.

\footnotetext{
2 The World Economic Outlook (WEO) of the International Monetary Fund (IMF) of April 2009 forecast output at 5 percent below potential, and inflation below 0.5 percent during 2009-10 in major advanced countries, and found a high probability of zero policy rates in the United States, the Euro Area, and Japan until 2011.

${ }^{3}$ For the purposes of this paper, an economy is said to be in a liquidity trap when nominal interest rates on short-term assets have been driven to zero. Blanchard (2003) concludes that, since the mid-1990s, "Japan has, in effect, been in a liquidity trap.”
} 
Figure 1. The Japanese Economy Since 1990
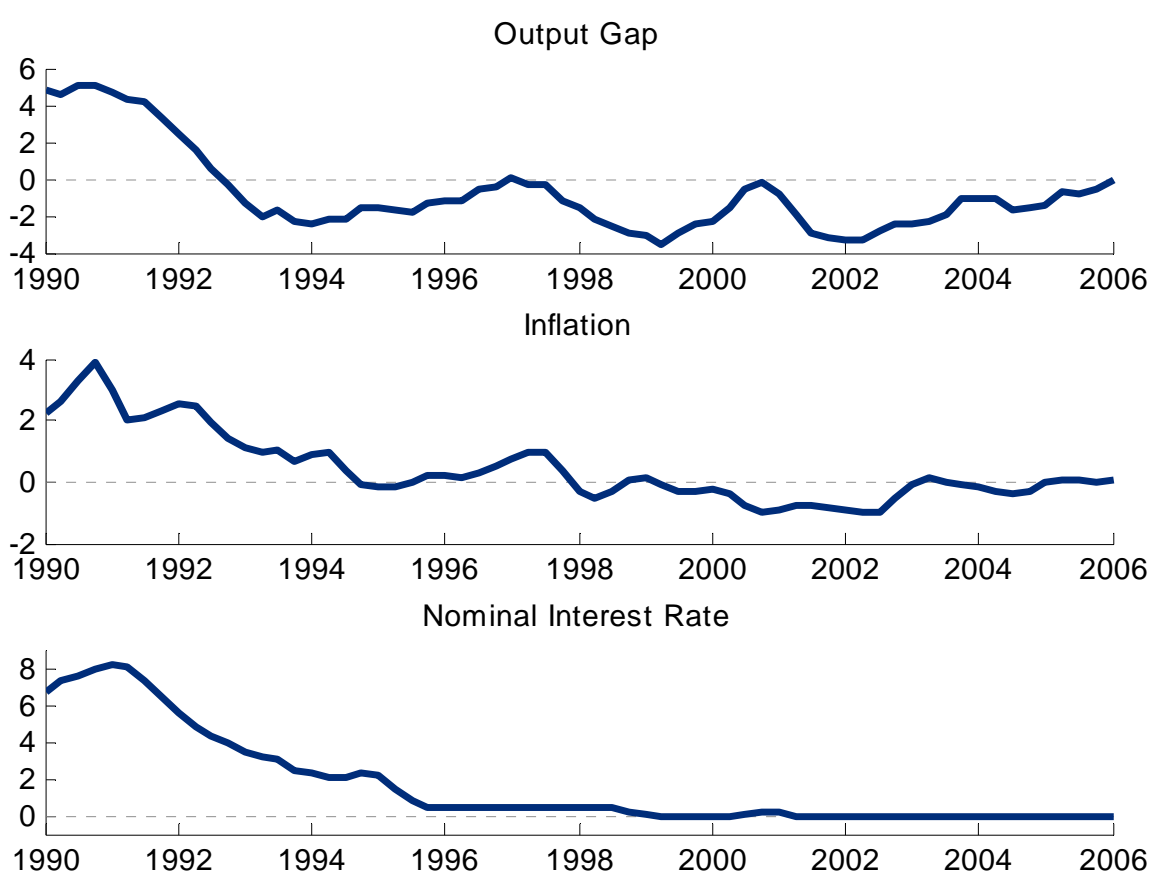

Note: Figure reports quarterly annualized CPI inflation (excluding fresh food), and the nominal call money interest rate, and the output gap prepared by Bank of Japan staff.

My first finding is that, as in Ahearne et al. (2002), Japanese interest rates fit a forwardlooking Taylor rule that implicitly targets inflation. A new result is that the implicit inflation target declined from about 2.5 percent in the early 1980s to near 1 percent in the mid-1990s. However, such an emphasis on low inflation was not strikingly unusual at the time. For example, at the 1996 Jackson Hole conference that brought together central bankers and financial market representatives, “[p]articipants at the symposium agreed that low or zero inflation is the appropriate long-run goal for monetary policy” (Kahn, 1996, p.ix).

Secondly, the estimation results indicate a number of adverse shocks over the 1990s. The natural rate of interest declined sharply in the early 1990s, hampering efforts to stimulate the economy by cutting the policy rate. In addition, contractionary demand shocks characterize the decade. These finding suggests that monetary policy was not the primary cause of the economy's poor performance. However, it does not follow that the Bank could have done nothing more to stabilize the economy.

In the counterfactual analyses, I try the following alternative interest-rate policy rules to see whether they could have helped Japan avoid the deflationary slump: (i) a policy rule with a higher inflation target, as originally suggested by Krugman (1998); (ii) a policy rule with a strong response to the output gap; (iii) a policy rule that combines a higher inflation target 
with a strong response to the output gap; and (iv) a price-level targeting rule along the lines of Eggertsson and Woodford (2003). The paper builds on existing research by investigating the effectiveness of these policy rules based on the historical series of estimated shocks for Japan during the 1990s and a structural model that displays plausible macroeconomic dynamics. ${ }^{4}$

The counterfactual simulations suggest that simply raising the inflation target to 4 percent but keeping everything else unchanged would have had only a short-lived positive effect on output. Similarly, a policy of simply responding more aggressively to the output gap while keeping the inflation target at the low estimated level would not have avoided deflation, and would have yielded limited improvement in output performance. Importantly, however, I find that a policy that both raised the inflation target to about 4 percent, and responded more actively to the output gap would have provided substantial support to output and avoided deflation. Finally, I find that a price-level targeting rule would have provided superior stabilization results.

An important consideration regarding the potential effectiveness of these alternative policy proposals is how to ensure that the associated policy announcements are believed. A number of existing studies analyze what actions the authorities can take to "demonstrate resolve," and strengthen the credibily of their policy announcements. ${ }^{5}$ The analysis in this paper appeals to this literature, and assumes that the authorities have already established a sufficient degree of credibility so that their policy announcements are believed. ${ }^{6}$

Part 2 of the paper presents estimation results for the structural model used to assess the conduct of monetary policy. Based on the estimated model, Part 3 conducts the counterfactual policy simulations. Part 4 concludes the paper, and considers how the lessons from Japan's experience relate to the current crisis.

\footnotetext{
${ }^{4}$ For example, the paper builds on Eggertsson and Woodford (2003) who demonstrate the benefits of price targeting using a purely forward-looking calibrated model, and a single shock to the natural rate of interest, by testing the effectiveness of alternative policy rules based on an estimated structural model with a mix of backward- and forward-looking behavior, and the series of shocks extracted from the data.

${ }^{5}$ For example, Eggertsson (2006b) suggests that the announcement of raising the price level can be made credible by accompanying it with an expansion of the money supply by the central bank, and the issuance of nominal debt by the government. In addition, Eggertsson (2008) finds evidence that such a strategy worked in the case of the United States in 1933. He concludes that the credibility of Roosevelt's announcement of an inflationary policy was strengthened by abandoning the gold standard and issuing government debt.

${ }^{6}$ Exploring the impact of Bank of Japan announcements on private-sector expectations is beyond the scope of this paper. For existing studies related to this issue, see, for example, Baba et al. (2005), and Okina and Shiratsuka (2004).
} 


\section{EMpirical ANALYSIS}

In this section, I investigate how the Bank of Japan conducted interest-rate policy as economic conditions deteriorated in the 1990s. Using a Bayesian approach, the section estimates the interest-rate reaction function of the Bank of Japan jointly with a structural model of the economy.

\section{A. Model Specification}

The analysis is based on a stylized New Keynesian model that features nominal and real rigidities, and can be summarized by the following three key equations

$$
\begin{aligned}
& x_{t}-\not x_{t-1}=E_{t-1}\left(x_{t+1}-\not x_{t}\right)-\sigma E_{t-1}\left(r_{t-1}-\bar{\pi}_{t+3}-r_{t-1}^{*}\right)+g_{t} \\
& \hat{\pi}_{t}-\lambda \hat{\pi}_{t-1}=\beta E_{t-1}\left(\hat{\pi}_{t+1}-\lambda \hat{\pi}_{t}\right) \dashv \kappa E_{t-1} x_{t} \dashv z_{t} \\
& r_{t}=\max \left\{0, \phi_{r} r_{t-1}+\left(1-\phi_{r}\right)\left(E_{t-1}\left(r_{t}^{*}+\pi_{t}^{*}\right)+\phi_{\pi} E_{t-1}\left(\bar{\pi}_{t+4}-\pi_{t}^{*}\right)+\phi_{x} E_{t-1} x_{t}\right)+\varepsilon_{t}^{r}\right\}
\end{aligned}
$$

where $x_{t}$ is the output gap, i.e., the deviation of output from potential, $r_{t}$ is the nominal interest rate, $\pi_{t}$ is the rate of inflation, and each period, $t$, corresponds to a quarter. ${ }^{7}$ The rate of inflation over one quarter is denoted by $\pi_{t}=\log \left(P_{t} / P_{t-1}\right)$, where $P_{t}$ is the price level, while the average rate of inflation over four quarters is denoted by $\bar{\pi}_{t}=\log \left(P_{t} / P_{t-4}\right)$, and the term $\hat{\pi}_{t}$ denotes the deviation of inflation from its steady-state level, i.e., $\hat{\pi}_{t}=\pi_{t}-\pi_{t}^{*}$. The “max" operator indicates that nominal interest rates cannot fall below zero. These equations, with the exception of the zero lower bound on nominal interest rates, represent log-linear approximations of a micro-founded dynamic general-equilibrium model in the spirit of Boivin and Giannoni (2006), and Smets and Wouters (2007).

Equation (1) is an intertemporal IS equation for aggregate output that reflects the private sector's optimal choice of expenditure and savings. Real output depends negatively on the lagged real interest rate, and positively on past and expected future output, due to habit persistence. ${ }^{8}$ Coefficient $\sigma$ represents the intertemporal elasticity of substitution. Following Boivin and Giannoni (2006), and Woodford (2003), equation (1) assumes that private-sector expectations are determined on the basis of information available at date $t-1$, as indicated by the conditional expectations operator $E_{t-1}$. The addition of this information lag, together with the presence of habit formation, allows the model to display plausible degrees of output persistence. $g_{t}$ is an exogenous real-demand disturbance that can be interpreted as a

\footnotetext{
${ }^{7}$ For the purposes of this paper, potential output is defined as the level of output that is consistent with stable inflation.

${ }^{8}$ As explained in Boivin and Giannoni (2006), the presence of lagged output in the IS equation can also reflect adjustment costs in investment expenditure.
} 
government consumption shock, and is assumed to follow an AR(1) process with a coefficient of $\rho_{g}$ :

$g_{t}=\rho_{g} g_{t-1}+\varepsilon_{t}^{g}$

where the innovation $\varepsilon_{t}^{g}$ is assumed to have a mean-zero Normal distribution with a variance of $\sigma_{\varepsilon_{g}}^{2}$. The term $r^{*}$ represents a time-varying Wicksellian "natural rate of interest," the real interest rate in the case that output is at its steady state, and inflation is stable. Changes in the natural rate of interest are assumed to be exogenous to the model but can be interpreted as reflecting changes in the rate of technological progress, or, following Curdia and Woodford (2008), changes in financial-sector stress. Following a number of studies, the natural rate of interest is assumed to follow an AR(1) process with a persistence parameter of $\rho^{r^{*}}$, and a long-run value of $\bar{r}^{*}$ :

$r_{t}^{*}=\rho_{r^{*}} r_{t-1}^{*}+\left(1-\rho_{r^{*}}\right) \bar{r}^{*}+\varepsilon_{t}^{r^{*}}$

where the innovation $\varepsilon_{t}^{r^{*}}$ is assumed to have a mean-zero Normal distribution.

The aggregate supply side of the model features nominal rigidities that permit monetary policy to have real effects. In particular, prices are sticky due to Calvo-style rigidities that allow only a fraction of firms re-optimize their prices every period. In addition, following a number of studies, if a price is not re-optimized, it is assumed to be indexed to lagged inflation. ${ }^{9}$ The resulting inflation dynamics are described by equation (2) in which inflation depends positively on past and future expected inflation, and on the output gap. ${ }^{10}$ Following Boivin and Giannoni (2006), firms base their decisions on information available in period $t$ 1. This information assumption, together with the presence of indexation to past inflation, permits the model to display a plausible degree of inflation persistence. ${ }^{11} z_{t}$ is a supply disturbance that can be interpreted as measuring exogenous changes in the marginal costs of production, and is assumed to follow an AR(1) process with persistence parameter $\rho_{z}$ :

\footnotetext{
${ }^{9}$ See for example, Smets and Wouters (2007), and Rabanal and Ramirez (2005).

${ }^{10}$ In the absence of price indexation, with $\lambda=0$, equation (2) reduces to the standard New Keynesian Phillips curve, where $\beta$ denotes the firm's discount factor. Because steady-state inflation can, here, differ from zero, it is necessary to specify equation (2) in terms of deviations from the steady-state level.

${ }^{11}$ As discussed by Rabanal and Ramirez (2005), adding price indexation improves the empirical fit of the New Keynesian aggregate supply relation.
} 
$z_{t}=\rho_{z} z_{t-1}+\varepsilon_{t}^{z}$

where the innovation $\varepsilon_{t}^{z}$ is assumed to have a mean-zero Normal distribution. Finally, equation (3) is a forward-looking Taylor rule that describes the central bank's interest-rate policy. The interest rate responds systematically to deviations of the inflation forecast for average four-quarter inflation from the implicit target, and can also respond explicitly to the output gap. Expectations are conditional on information available in period $t-1$, in line with the notion that policymakers respond to real-time estimates of the unobserved current-quarter state of the economy. Equation (3) also includes an interest-rate smoothing parameter, $\phi_{r}$, and an exogenous and unanticipated deviation from the policy rule, $\varepsilon^{r}$, which follows a meanzero Normal distribution.

A difference between equation (3) and existing work on Japanese monetary policy is that the implicit inflation target is allowed to vary over time. This possibility of a changing implicit inflation target is supported by recent empirical work. ${ }^{12}$ A simple AR(1) process captures time-variation of the implicit inflation target, with persistence parameter $\rho^{\pi^{*}}$, and a steadystate value of $\bar{\pi}^{*}$ :

$\pi_{t}^{*}=\rho_{\pi^{*}} \pi_{t-1}^{*}+\left(1-\rho_{\pi^{*}}\right) \bar{\pi}^{*}+\varepsilon_{t}^{\pi^{*}}$

where the innovation $\varepsilon_{t}^{\pi^{*}}$ is assumed to have a mean-zero Normal distribution.

The model is solved using standard methods, and the non-negativity constraint is imposed using the procedure of Reifschneider and Williams (2000). In particular, the linear model described by equations (1)-(7) is first solved while abstracting from the zero interest rate floor following the approach of Sims (2002). The zero interest rate floor is then imposed on the model solution following Reifschneider and Williams (2000) by augmenting the nominal interest-rate equation with additive disturbances for the current period and for a finite number of future periods. These disturbances equal zero if the policy rule implies a positive interest rate, and equal the absolute value of the unconstrained rate if the rule implies a negative value. Importantly, this procedure ensures that expectations of the future nominal interest rate cannot be negative up to a finite number of future periods. Details of the solution procedure are provided in the appendix.

\footnotetext{
${ }^{12}$ Kuzin (2006) provides evidence that the Bundesbank’s inflation target changed substantially during 19751998. Leigh (2008) finds evidence of significant time-variation in the Federal Reserve's implicit inflation target.
} 


\section{B. Model Estimation}

\section{Bayesian Estimation}

The parameters of the model are estimated jointly using Bayesian techniques, using quarterly data for output, inflation, and nominal interest rates for 1981Q3-1995Q4. The sample starts after inflation had declined to 4 percent from the double-digit levels observed in the 1970s. The sample ends in 1995Q4 as interest rates were at or near the zero bound after that date. ${ }^{13}$ The series for prices is the seasonally-adjusted consumer price index (CPI) excluding fresh food obtained from the Bank of Japan. ${ }^{14}$ There were two jumps in the price level in 1989Q2 and in 1997Q2 due to changes in the consumption tax. Since monetary policymakers probably do not respond to purely tax-induced inflation changes, I use the consumption- and tax-adjusted inflation series constructed by the Bank of Japan. To avoid problems associated with using the Hodrick-Prescott filter to estimate the output gap in the case of Japan, as discussed by a number of studies, I use output-gap estimates prepared by Bank of Japan staff using a production-function approach and data on capital and labor (Hara et al., 2006). The uncollateralized interbank overnight nominal call money rate is assumed to be the instrument that corresponds to the policy rate in the model.

The Bayesian estimation approach outperforms maximum likelihood estimation in small samples, and has the advantage of combining information contained in observable data with prior information regarding the distribution of the parameters. The selection of priors follows the existing literature. ${ }^{15}$ For the stochastic processes, the standard errors of the innovations are assumed to follow an inverse-gamma distribution which ensures that they are positive. The prior means have loose priors, with standard deviations of two. The prior means for the standard errors of the innovations to $r^{*}$ and $\pi^{*}$ are one-tenth of those for the other shocks, based on existing studies. ${ }^{16}$ The persistence of the AR parameter for demand and supply shocks is beta distributed, which ensures that they lie between zero and one, with mean 0.5 and a standard deviation of 0.2 . For the $r^{*}$ and $\pi^{*}$ processes, a more peristent AR parameter is assumed, again based on existing studies. The quarterly long-run natural rate of

\footnotetext{
${ }^{13}$ Sugo and Ueda (2008) use the same sample of analysis.

${ }^{14}$ The CPI (excluding fresh food) appears to be the Bank of Japan's preferred price indicator, as suggested by the prominence it receives in the monthly "Statement on Monetary Policy."

${ }^{15}$ See, for example, Smets and Wouters (2007), and Rabanal and Ramirez (2005) who estimate structural models based on U.S. data, and Sugo and Ueda (2008) who estimate a structural model based on Japan data.

${ }^{16}$ Laubach and Williams (2003) find that innovations to the natural rate of interest have a standard error that is about one tenth the magnitude of the standard error of the shock to the intertemporal IS equation. They also find that the natural rate of interest process is highly persistent with a persistence parameter close to unity. Similarly, Leigh (2008) finds that, for the United States, the ratio of the innovation to the inflation target and the innovation to the monetary policy rule is about on tenth.
} 
interest is assumed to have a Normal distribution with mean of 0.75 percent per quarter, and standard deviation 0.1 . This value corresponds to 3 percent on an annual basis, and is close to the average observed over 1981-1995. ${ }^{17}$ The steady-state inflation value for the inflation target, $\bar{\pi}^{*}$, is assumed to have a Normal distribution with a mean of 0.5 percent per quarter ( 2 percent per annum) and standard deviation of 0.1 percent.

The priors for the interest-rate policy function parameters are based on the Taylor (1993) rule. The long-run reaction to the inflation forecast is assumed to have a Normal distribution with a mean of 1.5 and a standard deviation of 0.125 . The output response parameter is assumed to have an inverse-gamma distribution with a mean of 0.125 and a standard deviation of 0.125 . A parameter of 0.125 based quarterly interest rates is consistent with a parameter of 0.5 on annual data, as in Taylor (1993). The interest-rate smoothing parameter is assumed to have a beta distribution with a mean of 0.75 , and a standard error of 0.1 .

Turning to the structural parameters in the inter-temporal IS and New-Keynesian aggregate supply equations, they are chosen to be consistent with values typically found in the literature. The habit-persistence parameter, $\gamma$, is assumed to have a beta distribution with a mean of 0.5 . The intertemporal elasticity of substitution, $\sigma$, is set at 0.5 , and the prior for the Phillips curve slope coefficient, $\kappa$, is set at 0.02, based on Eggertsson and Woodford (2003). The parameter on the degree of price indexation in the New-Keynesian aggregate supply equation has a prior mean of 0.5 . The parameter $\beta$ is fixed at 0.995 in the estimation procedure, in line with Sugo and Ueda (2008).

To obtain estimation results, the posterior estimates of the vector of parameters, denoted by $\Phi=\left\{\phi_{\pi}, \phi_{x}, \phi_{r}, C, \gamma, \kappa, \lambda, c_{\varepsilon_{g}}, C_{\varepsilon_{z}}, C_{\varepsilon_{r}}, C_{\varepsilon_{\pi^{*}}}, C_{\varepsilon_{r^{*}}}, \bar{\pi}^{*}, \bar{r}^{*}, \rho_{g}, \rho_{z}, \rho_{\pi^{*}}, \rho_{r^{*}},\right\}$ is derived by applying standard Bayesian methods. ${ }^{18}$ The mode of the posterior distribution is estimated by maximizing the log posterior function, which combines the prior information on the parameters with the likelihood of the data. Finally, the posterior distribution of the parameters, including the mean and the 95-percent confidence interval, is obtained using a Metropolis-Hastings algorithm.

\footnotetext{
${ }^{17}$ The ex-post real interest rate (nominal interest rate minus actual future inflation) over 1981Q3-1995Q4 is 3.6 percent.

${ }^{18}$ In particular, the approach follows Rabanal and Ramirez (2005). Estimates are obtained using two blocks of 100,000 replications each, of which the first 20 percent were discarded. A step size of 0.5 resulted in a rejection rate of 0.70 , a standard value. The estimation was conducted using DYNARE.
} 


\section{Estimation Results}

\section{Monetary Policy Parameters}

Given the focus of this paper on monetary policy, the disussion starts with the estimated interest-rate reaction function. Table 1 reports the estimated posterior mean, and 95-percent confidence intervals for each parameters, as well as the corresponding prior assumptions. The long-run reaction to inflation, $\phi_{\pi}$, has an estimated mean of 1.7 , and a 95-percent confidence interval greater than one, consistent with a strong emphasis on inflation stabilization. The output gap-stabilization parameter is estimated at 0.09 , consistent with a modest degree of output stabilization. In addition, the mean of the interest-rate smoothing coefficient is estimated at 0.7. These results are similar to those obtained in the literature for other central banks, as in Clarida, Gali and Gertler (1997).

Regarding the implicit inflation target, the results provide evidence of a downward drift in the target from about 2.5 percent in the early 1980s to about 1 percent by 1995 . An implicit target of about 1 percent is consistent with available narrative evidence. Eiko Shinotsuka, a member of the policy board of the Bank of Japan said that the "Bank should aim at zero inflation" (Shinotsuka, 2000) except to the extent that there are biases in the measurement of inflation. Shiratsuka (1999) estimates that the measurement bias in CPI inflation in Japan is about 0.9 percent per annum (Shiratsuka, 1999). Moreover, a recent Bank of Japan publication states: "The 'understanding of medium- to long-term price stability' —reviewed annually in principle and expressed in terms of the year-on-year rate of change in the CPIwas reviewed in April 2009 and falls in the range approximately between 0 and 2 percent, with most Policy Board members' median figures at around 1 percent” (Bank of Japan, May 2009). The finding of a declining path for the implicit inflation target during this period is consistent with findings for other central banks. ${ }^{19}$

\footnotetext{
${ }^{19}$ For example, Kuzin (2006) finds that the ECB lowered its inflation goal from more than 4 percent in 1975 to near 2 percent in 1998. Leigh (2008) finds that the Federal Reserve's implicit inflation target declined from about 3 percent in the early 1980s to close to 2 percent by the mid-1990s.
} 
Table 1. Estimation Results

\begin{tabular}{|c|c|c|c|c|c|c|}
\hline & \multicolumn{3}{|c|}{ Prior Distribution } & \multicolumn{3}{|c|}{ Posterior Distribution } \\
\hline & Distribution & Mean & St. Dev. & Mean & Lower Bound & Upper Bound \\
\hline$\phi_{\pi}$ & Normal & 1.500 & 0.250 & 1.715 & 1.358 & 2.078 \\
\hline $4_{x}$ & Invgamma & 0.125 & 0.125 & 0.092 & 0.041 & 0.144 \\
\hline$\varphi_{r}$ & Beta & 0.750 & 0.100 & 0.738 & 0.648 & 0.823 \\
\hline$\sigma$ & Invgamma & 0.500 & 0.100 & 0.424 & 0.317 & 0.526 \\
\hline$\gamma$ & Beta & 0.500 & 0.100 & 0.751 & 0.651 & 0.860 \\
\hline$\kappa$ & Invgamma & 0.020 & 0.001 & 0.019 & 0.016 & 0.022 \\
\hline$\lambda$ & Beta & 0.500 & 0.100 & 0.623 & 0.474 & 0.775 \\
\hline$\sigma_{\varepsilon} g$ & Invgamma & 1.000 & 2.000 & 0.280 & 0.200 & 0.350 \\
\hline$\sigma_{\varepsilon} z$ & Invgamma & 1.000 & 2.000 & 0.150 & 0.120 & 0.170 \\
\hline$\sigma_{\varepsilon} r$ & Invgamma & 1.000 & 2.000 & 0.150 & 0.130 & 0.180 \\
\hline$\sigma_{\varepsilon} \pi^{*}$ & Invgamma & 0.100 & 2.000 & 0.050 & 0.030 & 0.070 \\
\hline$\sigma_{\varepsilon} r^{*}$ & Invgamma & 0.100 & 2.000 & 0.100 & 0.040 & 0.170 \\
\hline $\bar{\pi}^{*}$ & Normal & 0.005 & 0.001 & 0.005 & 0.003 & 0.006 \\
\hline $\bar{r}^{*}$ & Normal & 0.007 & 0.001 & 0.007 & 0.006 & 0.009 \\
\hline$\rho_{\varepsilon} g$ & Beta & 0.500 & 0.100 & 0.643 & 0.539 & 0.749 \\
\hline$\rho_{\varepsilon} z$ & Beta & 0.500 & 0.100 & 0.290 & 0.193 & 0.388 \\
\hline$\rho_{\pi^{*}}$ & Beta & 0.950 & 0.025 & 0.957 & 0.924 & 0.991 \\
\hline$\rho_{r^{*}}$ & Beta & 0.950 & 0.025 & 0.961 & 0.933 & 0.991 \\
\hline
\end{tabular}

Note: Table reports the assumed prior distribution, and the estimation results for the mean and the 95percent confidence interval of the posterior distribution ("lower" and "upper" bounds). The posterior distribution is obtained using the Metropolis-Hastings algorithm. The parameters denoting the standard deviations of the shocks are expressed in percent. 
Figure 2. Estimation Results: Implicit Inflation Target

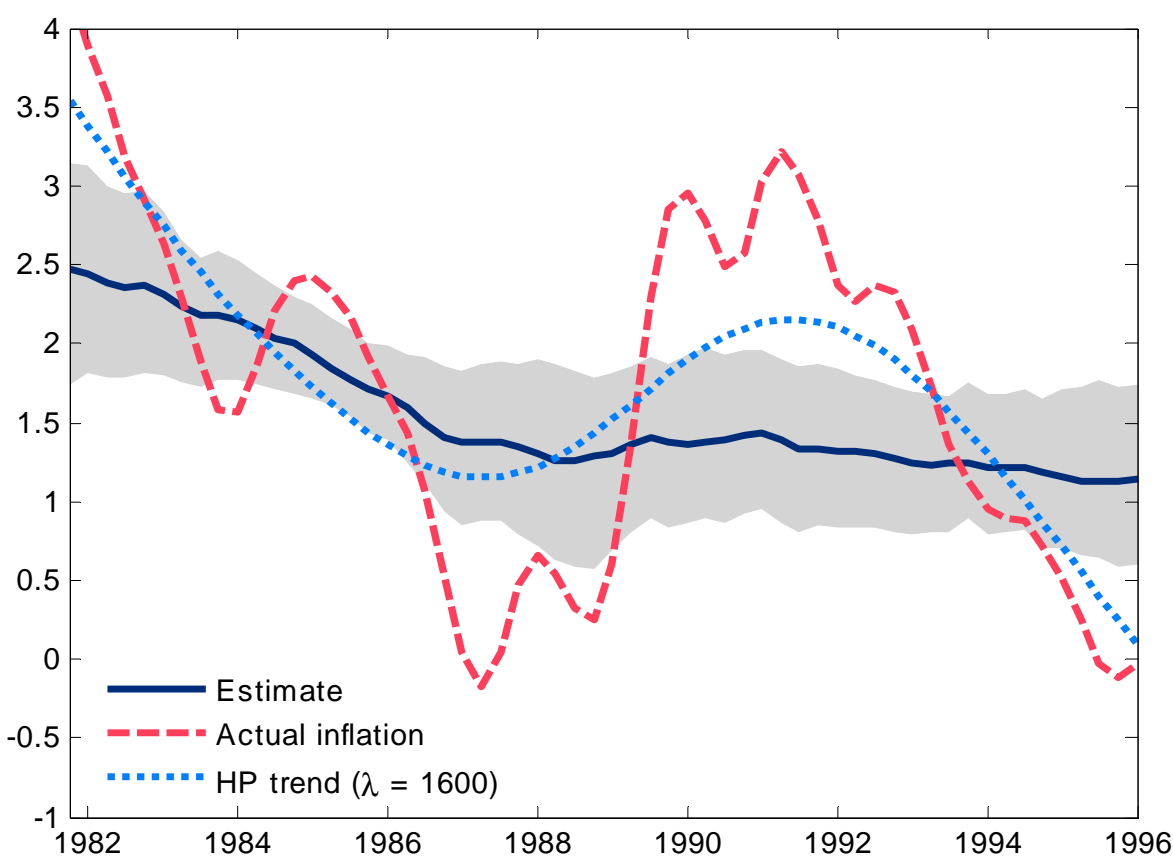

Note: The solid line indicates the median of the estimated posterior distribution. The shaded area indicates the 95-percent confidence band.

Regarding the natural rate of interest, a key element of the policy reaction function, the estimates displayed in Figure 3 suggests that it declined from about 4 percent in the early 1980s to about 1 percent by the mid-1990s. The decline was particularly sharp after 1991, and the estimate is not significantly different from zero by 1995Q4. This sharp decline in the natural rate coincides with the bursting of the asset-price bubble, and could following Curdia and Woodford (2008), and Gertler (2003), be interpreted as an increase in financial-sector stress. ${ }^{20}$ The figure also illustrates how a decline in the natural rate complicates the task of easing monetary policy. On average, despite substantial interest-rate cuts the actual real policy rate remained above the natural rate during 1991-1995. ${ }^{21}$

\footnotetext{
${ }^{20}$ The decline in the natural rate in the 1990s is broadly consistent with Iwamura, Kudo and Watanabe (2006), although their estimated path is more jagged. For comparison, the graph also shows the trend of the real interest rate obtained using the Hodrick-Prescott filter with a smoothing parameter of 1600.

${ }^{21}$ The actual real policy rate in Figure 3 is the nominal rate minus the rational-expectations inflation forecast generated by the structural model.
} 
Figure 3. Estimation Results: Natural Rate of Interest

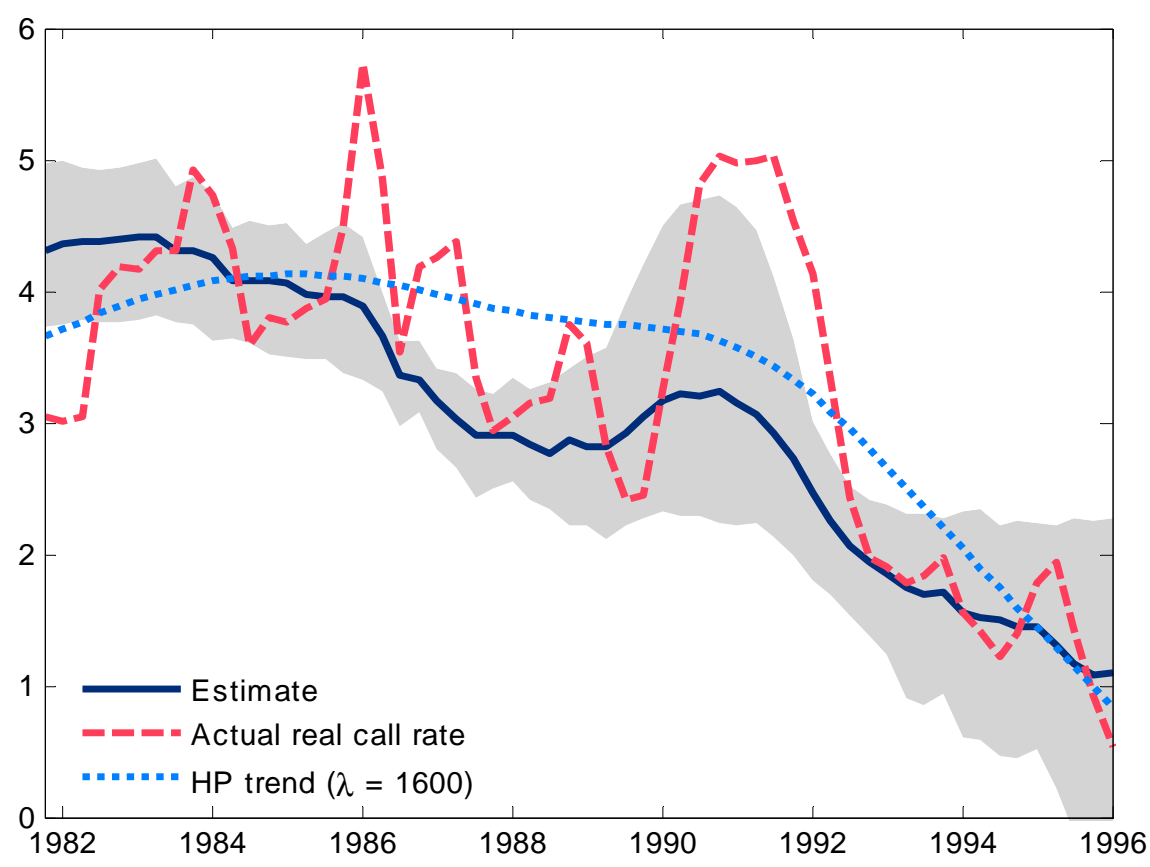

Note: The solid line indicates the median of the estimated posterior distribution. The shaded area indicates the 95-percent confidence band.

To measure how well the estimated policy rule fits actual Bank of Japan behavior, Figure 4 plots the actual policy rate along with the estimated target rate, and the 95-percent confidence band. The estimated target interest rate rate differs from fitted policy rate because it implicitly sets the interest-rate smoothing parameter to zero $\left(\phi_{r}=0\right)$. For each date, the value of the estimated target rate is based on the reaction-function coefficients, and the model-consistent forecasts of output and inflation. Because the target rate abstracts from interest-rate smoothing, the actual policy rate tends to follow the target with a lag. Such gradualism is particularly noticeable during the boom of the late $1980 \mathrm{s.}^{22}$ After the boom, during 1991-92, the path of the actual policy rate is not significantly different that prescribed by the estimated target. ${ }^{23}$ After 1992, the policy rate again lags the estimated target. Note that the tendency of the actual rate to lag the target rate, sometimes substantially, is not unique to the Bank of Japan. As Clarida, Gali, and Gertler (1997) report, the Bundesbank displayed a

\footnotetext{
${ }^{22}$ Bernanke and Gertler (1999) attribute the stock market bubble in the pre-1990 period to this delay in tightening.

${ }^{23}$ Other studies, including Bernanke and Gertler (1999) find larger declines in the estimated target rate, with the and actual policy rate well above the target rate during 1991-1992. However, these studies are based on ex-post actual future inflation that declined faster than expected in real-time.
} 
strong degree of policy inertia during the 1980s and 1990s, with the actual interest rate consistently lagging the target rate.

Figure 4. Estimated Policy-Rate Target and Actual Policy Rate

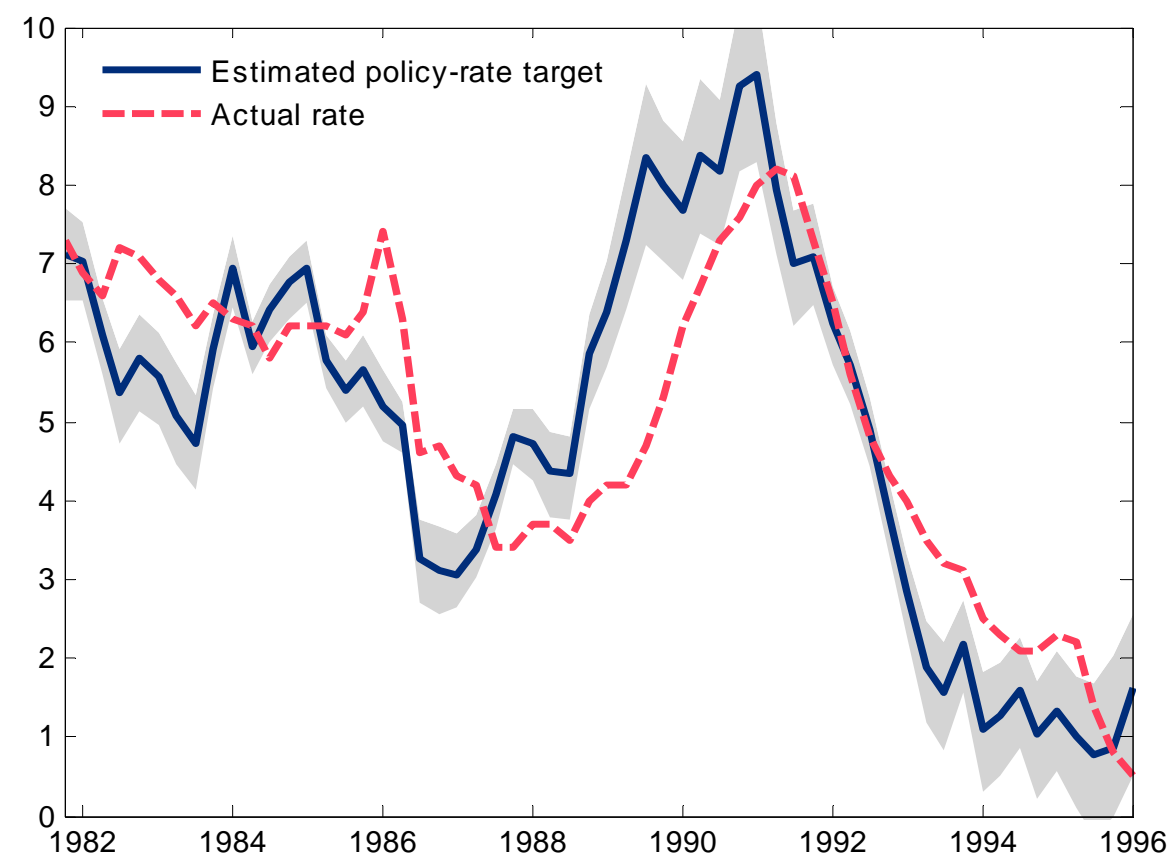

Note: The solid line indicates the median of the estimated posterior distribution. The shaded area indicates the 95-percent confidence band for the estimate.

Overall, the results suggests that there was nothing “exceptional” about Japanese interest-rate policy during the early 1990s. A new finding is that the implicit inflation target declined to near 1 percent. However, the accepted consensus at the time was that central banks ought to aim for a low inflation level. While the implicit target of 1 percent estimated here for the Bank of Japan might be towards the lower range of what most central bankers in the 1990s regarded as desirable, it was by no means a strikingly unusual objective. Indeed, an even lower inflation rate was seen by some as preferrable. Wim Duisenberg, who was Governor of the central bank of the Netherlands during 1982-1997 said: "In the 16 years that I was the Governor of the central bank of the Netherlands, there were two years in which we had deflation of $1 / 2 \%$. I publicly declared then that I lived in a central banker's paradise” (Duisenberg, 2003). Feldstein (1996) emphasized that a zero target for measured inflation was preferrable than a low but positive target, and estimated that the cost of 2 percent inflation rather than zero inflation amounts to about 1 percent of GDP per year. 


\section{Structural Model Parameters}

Having discussed the estimation results for monetary policy, the discussion shifts to the remaining parameters of the model. In the IS equation, the intertemporal elasticity of substitution, $\sigma$, has an estimated posterior mean of 0.4 which is towards the lower range of estimates in the literature, implying that monetary policy has a relatively modest effect on output. $^{24}$ The habit-formation parameter, $\gamma$, has estimated posterior mean of 0.7 , and is significantly greater than the prior of 0.5 , implying substantial persistence in expenditure. In the aggregate supply equation, the degree of price indexation has an estimated prior mean of 0.6 , and the slope coefficient, $\kappa$, has an estimated mean of 0.02 , consistent with the estimates for Japan of Sugo and Ueda (2008). The estimated parameters for the exogenous shock variables are similar to the prior assumptions.

Finally, to assess whether the estimated model displays a plausible degree of output, inflation, and interest-rate persistence, Figure 5 compares the autocorrelation functions based on the estimated model with those found in the actual data. The model tracks the autocorrelation functions of inflation and interest rates closely, but generates less output persistence than implied by the data.

\footnotetext{
${ }^{24}$ Note that a $\sigma$ of 0.4 relative to the quarterly interest rate is consistent with a $\sigma$ of only 0.1 relative to the annualized interest rate, which is below estimates typically reported in the empirical literature on the intertemporal elasticity of substitution (see, for example, Okubo, 2008, and Ogaki and Reinhart, 1998, who base their results on U.S. data).
} 
Figure 5. Autocorrelation Functions

Data, and Model (- -)
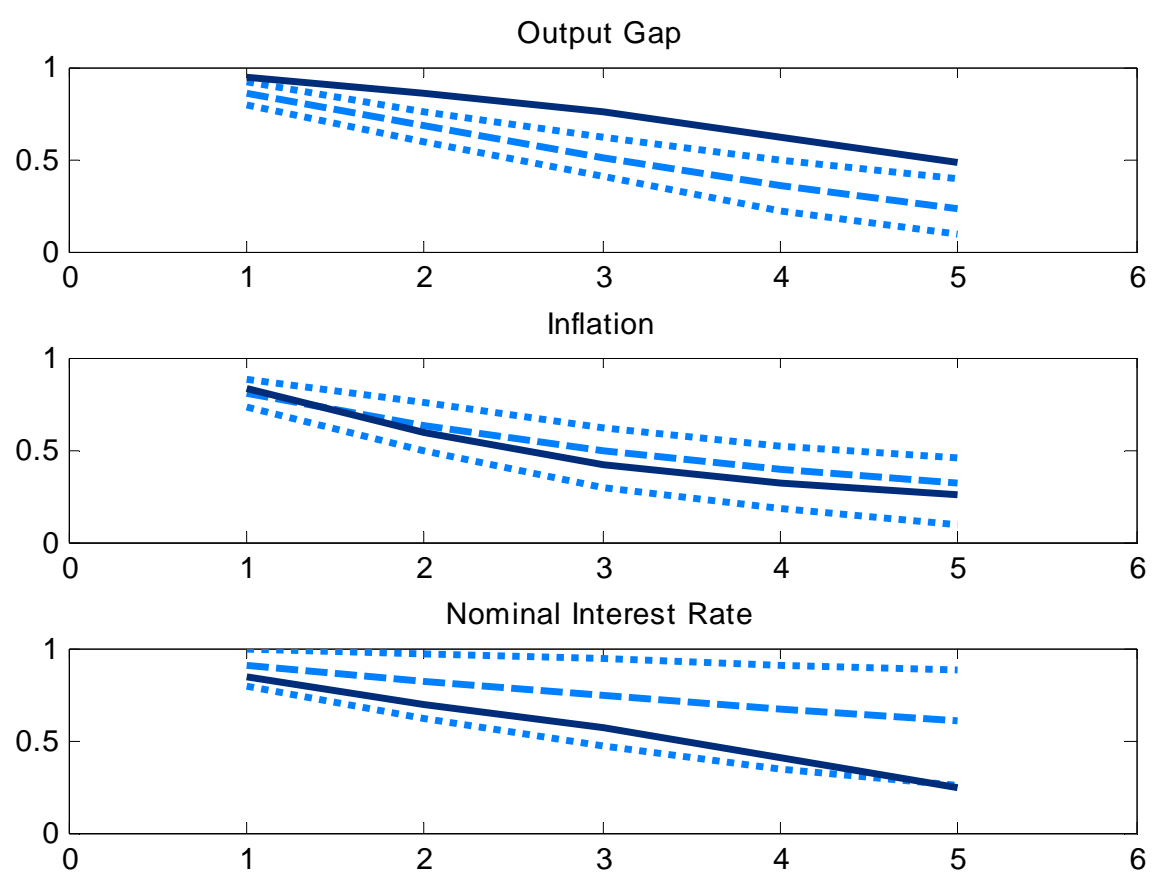

Notes: Solid line denotes autocorrelations based on Japan data for the sample of analysis. Dashed line indicates autocorrelations based on the posterior mean of the estimated model. Dotted lines indicate 95-percent confidence bands.

\section{Counterfactual Analysis}

Having estimated the structural model, I conduct counterfactual exercises to investigate whether alternative interest-rate policy approaches could have helped Japan to improve macroeconomic performance. ${ }^{25}$ The counterfactual simulations start in 1993Q1, as the output gap becomes negative in the aftermath of the asset-price collapse, and end in 2006Q1 by which time the output gap returns to zero. For each simulation, I report the average level of inflation during 1993Q1-2006Q1, as well as the cumulative output loss. The cumulative output loss is defined as the sum of the output gaps from 1993Q1-2006Q1 in percent of annual potential GDP.

In order to perform counterfactual simulations of the model, I first extract a time series for each of the exogenous disturbances $\left\{g, z, \varepsilon^{r}\right\}$ using the estimated model. ${ }^{26}$ To permit the

\footnotetext{
${ }^{25}$ Exploring the possible consequences of additional fiscal stimulus is beyond the scope of the paper.

${ }^{26}$ The process of extracting the structural shocks involves simulating the model and computing the time series of rational expectations while ensuring that the zero bound on nominal interest rates is respected.
} 
counterfactual analysis to extend beyond the end of the estimation sample in 1995Q4, the analysis assumes that the structural parameters reported in Table 1 remain unchanged thereafter. The analysis also assumes that the implicit inflation target and the natural rate of interest follow their estimated paths up to the end of the estimation sample (1995Q4), and remain at the values they reach i.e., about 1 percent, thereafter. The assumption that the implicit inflation target remains close to 1 percent after 1995Q4 is consistent with the narrative evidence discussed above. To address the possibility that the natural rate of interest declined further after 1995Q4, the analysis is repeated while assuming that the natural rate of interest falls to and remains at -1 percent per year after 1995Q4, and the results of the counterfactual experiements are similar. ${ }^{27}$ Similarly, to address the possibility that the interest-rate sensitivity of aggregate expenditure, $\sigma$, declined further from the already low estimated value of 0.4 , the analysis is repeated with $\sigma$ reduced by half $(\sigma=0.2)$. With this smaller value of $\sigma$, the improvement in output performance achieved with the alternative interest-rate rules declines but remains substantial. ${ }^{28}$ Using the derived shocks together with the structural equations of the model replicates the historical time series of all variables.

The behaviour of the real demand shocks entering the IS equation $\left(g_{t}\right)$ over the 1990s suggests that a substantial amount of "bad luck" characterizes the post-bubble period (Figure 6). The negative shocks in the early 1990s can be interpreted as reflecting the decline in investment spending that followed the bursting of the stock- and land-price bubbles in 199192. ${ }^{29}$ The shocks during 1997-99 appear to be associated with the banking crisis, the consumption tax hike, and the effects of the Asian financial crisis. The contractionary shocks starting in 2001 could reflect the recession that started after the collapse of the dot-com bubble in the United States.

The supply shocks entering the aggregate supply equation $\left(z_{t}\right)$ indicate a number of deflationary disturbances starting in the late 1990s. Such supply shocks are interpreted as benign under normal circumstances, reflecting declining markups and firm monopoly power. ${ }^{30}$ However, as Laxton, N’diaye and Pesenti (2006), and Eggertsson (2006a) explain,

\footnotetext{
${ }^{27}$ In particular, for each counterfactual simulation, the improvement in output performance achieved using each of the alternative policy rules does not decline when a natural rate of -1 percent per year after 1995Q4 is assumed. Iwamura, Kudo, and Watanabe (2006) estimate the natural rate of interest based on a reduced-form model along the lines of Laubach and Williams (2003), and find that during 1996Q1-2006Q1, the natural rate of interest averaged 0.9 percent per year during with a maximum of 2.5 percent per year, and a minimum of 1.8 percent per year.

${ }^{28}$ In particular, for each alternative rule, the improvement in output performance remains at more than 75 percent of the improvement achieved using the model with the estimated value of $\sigma=0.4$.

${ }^{29}$ For a discussion of the bursting of the asset price bubble in Japan, see, for example, Bernanke (2000).

${ }^{30}$ A number of observers attributed part of the deflation observed during the 1990s to supply-side shifts, as documented by Posen (2000).
} 
supply shocks that reduce inflation can, when nominal interest rates are at the zero lower bound, raise real interest rates and thus depress output. Finally, the exogenous interest rate shocks, $\varepsilon^{r}$ are close to zero during the 1990s.

Figure 6. Demand and Supply Shocks: 1990-2005

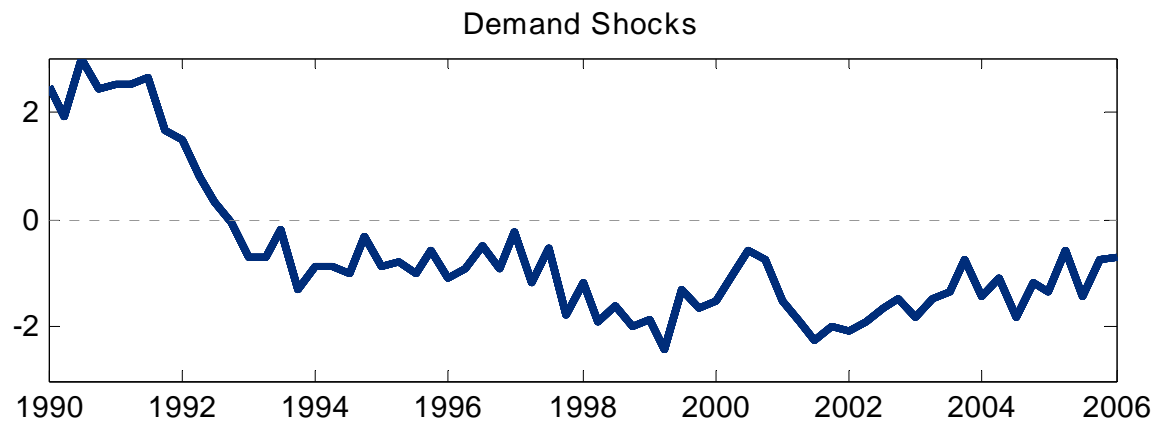

Supply Shocks

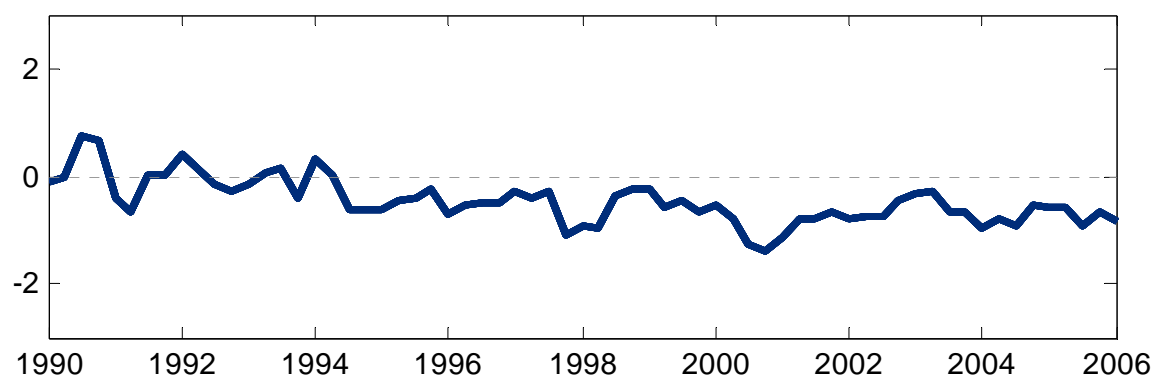

\section{Higher Inflation Target}

Having discussed the shocks, I now consider whether different policy rules could have improved macroeconomic performance. The first experiment examines how the economy would have evolved if the implicit inflation target had risen to 4 percent in 1993Q1, with everything else remaining unchanged. Krugman (1998) suggested a 4 percent inflation target for Japan to anchor inflation expectations well above zero and avoid deflation. ${ }^{31}$ Other things equal, a higher inflation target implies a higher steady-state nominal interest with more room for interest-rate cuts before reaching the zero bound. The estimated decline in the natural rate of interest in the 1990s underlines the need for such a higher inflation buffer.

\footnotetext{
${ }^{31}$ Several studies, such as Reifschneider and Williams (2000) and Hunt and Laxton (2003) find that an inflation target of greater than 2 percent reduces the probability of hitting the zero bound.
} 
Table 2. Actual and Counterfactual Inflation and Output Loss

\begin{tabular}{lcc}
\hline & Average Inflation & Output Loss \\
Actual & -0.01 & -22.6 \\
Counterfactual & & \\
Higher Inflation Target & 2.6 & -19.4 \\
Stronger Output-gap Response & 0.2 & -15.8 \\
Higher Inflation Target and Stronger Output-gap Response & 2.7 & -10.8 \\
Price Target & 1.1 & 1.4 \\
\hline
\end{tabular}

Notes: "Actual" refers to the data-based average inflation in percent per year and cumulative output loss relative to potential in percent of annual potential GDP over 1993Q1-2006Q1. "Higher inflation target" refers to an inflation target of 4 percent per year; "stronger response to output gap" refers to an output response parameter of $q_{x}=1$. "Price target" refers to a price-level target with a trend of 1 percent per year.

The results indicate that a 4 percent inflation target would have warded off deflation and prevented zero interest rates during 1993-1995. The increase in inflation from an actual average level of just below zero to a counterfactual average level of 2.6 percent occurs through three channels (Table 2 and Figure 7). First, the higher inflation target anchors inflation expectations at 4 percent, and this increase in expected inflation translates into higher inflation in line with the forward-looking component of the aggregated supply equation (2). Secondly, in the short run, the increase in inflation expectations reduces real interest rates because the nominal interest rate rises gradually towards its new long-run level. This short-run decline in real interest rates stimulates output for about two years (19931995), which in turn raises inflation further relative to the actual path. Finally, the reason that current-quarter inflation averages 2.6 percent rather than 4 percent is that the unexpected shocks to inflation are deflationary over almost the entire period of analysis. Note that because the effect of the shocks on inflation is expected to fade over the four-quarter-ahead forecasting horizon of the central bank, the response of policy interest rates to these shocks is minimal.

However, the associated improvement in output performance is short-lived and small. In particular, the cumulative output loss declines from an actual estimated loss of 22.6 percent of potential GDP to 19.4 percent of potential GDP, equivalent to a reduction of only one seventh. The reason for the limited improvement in output performance appears to be that the additional policy room created by the higher inflation target is not used more vigorously. In particular, the output response coefficient is assumed to remain at the estimated level of $\phi_{x}=0.09$. 
Figure 7. Actual and Counterfactual Macroeconomic Dynamics: Higher Inflation Target
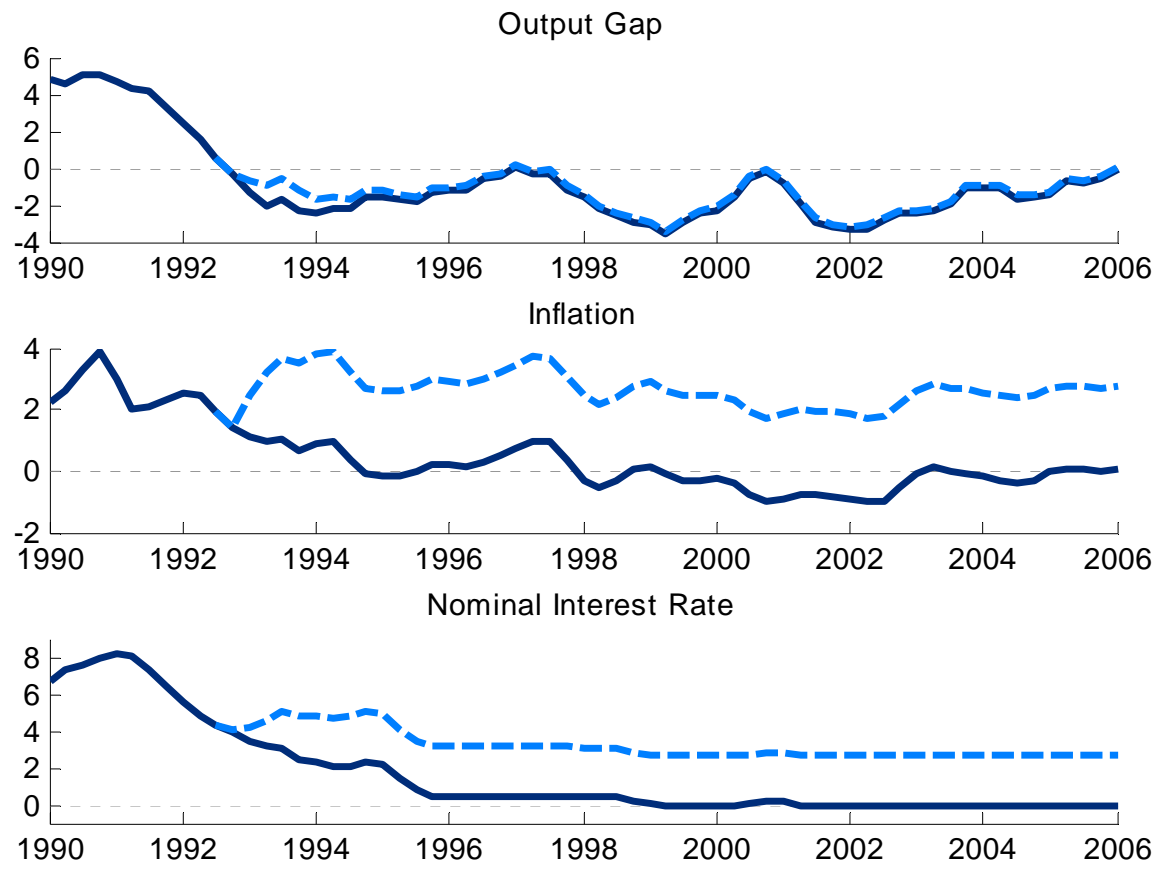

Notes: Figure reports actual path (solid line) of output gap, inflation, and interest rates, and simulated counterfacual path (dashes).

This first counter-factual policy experiment thus yields an important finding: simply raising the inflation target to 4 percent would not, of itself, have provided much support to output during the "Lost Decade." It also seems interesting to investigate whether a rule that responded more vigorously would have provided sufficient stimulus to avoid the large output losses.

\section{Stronger Output-Gap Response}

I now consider the performance of a Taylor rule that responds more vigorously to deviations of output from potential. While the inflation target is assumed to follow the estimated path, the output-response parameter, $\phi_{x}$, rises from the estimated value of 0.09 to a more "activist" value of 1.0 in 1993Q1. ${ }^{32}$ This experiment therefore addresses the critique of the Bank of Japan by a number of studies, including Bernanke and Gertler (1999), that it did not react strongly enough to the deflationary forces at work during the "Lost Decade."

\footnotetext{
${ }^{32}$ Note that a parameter of 1.0 based quarterly interest rates is consistent with a parameter of 4 on annual data, substantially more aggressive than the Taylor (1993) parameter of 0.5 .
} 
Figure 8. Actual and Counterfactual Macroeconomic Dynamics: Stronger Output Gap Response
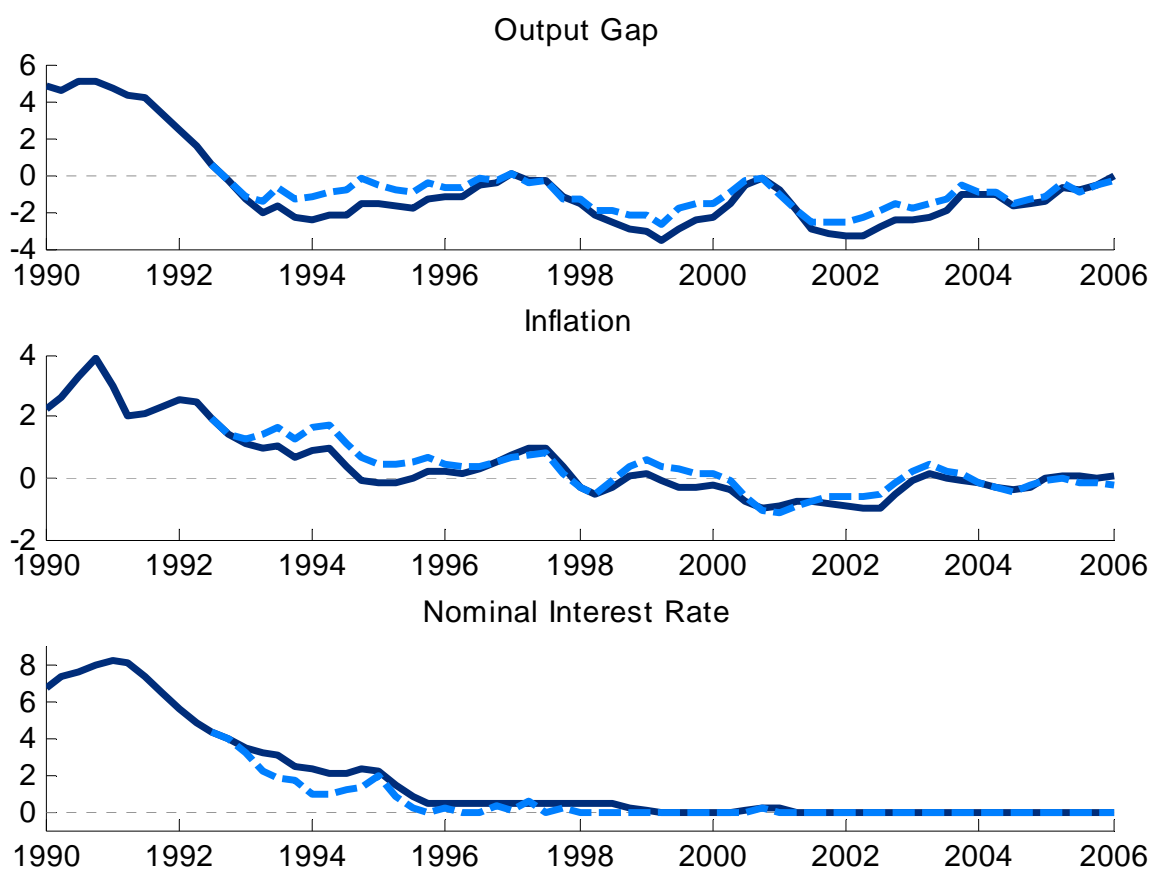

Note: figure reports actual path (solid line) of output gap, inflation, and interest rates, and simulated counterfacual path (dashes).

As Figure 8 illustrates, the counterfactual policy rate now falls faster in 1993, and reaches zero by 1995Q4, about three years before the actual policy rate reached zero. ${ }^{33}$ This additional monetary stimulus raises output during 1993-97, and inflation also rises above the actual level. After the onset of contractionary shocks in 1997 and 2001, output falls by less, although the policy interest rate-already at the zero bound — cannot respond. The additional stimulus provided during this period works primarily via the expectation that the policy rates will remain at zero for longer than under the estimated rule. Overall, the cumulative output loss with the stronger output response declines to 16 for the sample of analysis, compared to the actual estimated loss of 22.6 percent of potential GDP. This change represents a loss reduction of about 30 percent. In addition, while inflation rises slightly, averaging 0.2 percent per year, the economy still experiences several quarters of deflation.

This counterfactual experiment thus suggests another important result: a policy rule with a stronger response to the output gap but the original low inflation target would have provided

\footnotetext{
33 The actual call rate averaged 0.4 percent per year in 1998, before falling to an average of 0.06 percent per year in 1999 .
} 
a limited degree of stimulus. ${ }^{34}$ A natural next step thus seems to evaluate a rule that combines the two proposals and has both a higher inflation target and a stronger response to the output gap.

\section{Higher Inflation Target and Stronger Output-Gap Response}

Figure 9 reports the results of a counterfactual simulation using a policy rule that has both a higher inflation target of 4 percent, and the stronger output-gap response, $\phi_{x}=1$. The higher inflation target again anchors inflation expectations at 4 percent, and provides the central bank greater policy space for cutting interest rates. As before, the announcement of the higher inflation target in 1993Q1 itself stimulates output during the first two years. Inflation also rises towards the 4 percent target during this period.

Next, as the contractionary shocks arrive in and after 1997, and again after 2001, the central bank uses the additional policy space for interest-rate cuts. Consequently, following each adverse shock, the simulated path of output rebounds faster than does the actual historical path. Over the whole sample, the cumulative output loss is now only 10.8 percent, less than half the actual estimated output loss. Inflation now averages 2.7 percent per year. ${ }^{35}$ Nominal interest rates only hit the zero-bound constraint in three quarters, 2001Q4-2002Q2.

This counter-factual experiment thus yields a novel finding: a rule that combined the two policy components - a higher inflation target and a stronger response to the output gapwould have achieved superior stabilization results than any one of the components alone. The intuition for this finding is that the higher inflation target provides the policy space to cut interest rates in response to the deflationary shocks, while the stronger output-gap coefficient provides the "will" to use that additional space vigorously. ${ }^{36}$

\footnotetext{
${ }^{34}$ In particular, while the 30-percent output loss reduction achieved with a more aggressive response is greater than that achieved by simply raising the inflation target, the output loss remains at almost 16 percent of potential GDP (Table 2).

${ }^{35}$ This 2.7 percent average inflation rate is 0.1 percentage points per year greater than the average inflation rate under the simulation with a higher inflation target alone (Table 2). The increase is due to the greater degree of output loss reduction and the Phillips curve slope coefficient $\kappa$ estimated at 0.019 . Repeating the simulations while imposing a steeper slope parameter results in a larger inflation increase.

${ }^{36}$ As Table 2 reports, the reduction in the output loss, from the actual 22.6 percent of annual potential GDP to 10.8 percent of annual potential GDP, represents a loss reduction of 11.8 percentage points of annual potential GDP, greater than the sum of the two loss reductions associated with the two individual policy components (10 percentage points of annual potential GDP).
} 
Figure 9. Actual and Counterfactual Macroeconomic Dynamics: Higher Inflation Target and Stronger Output-gap Response
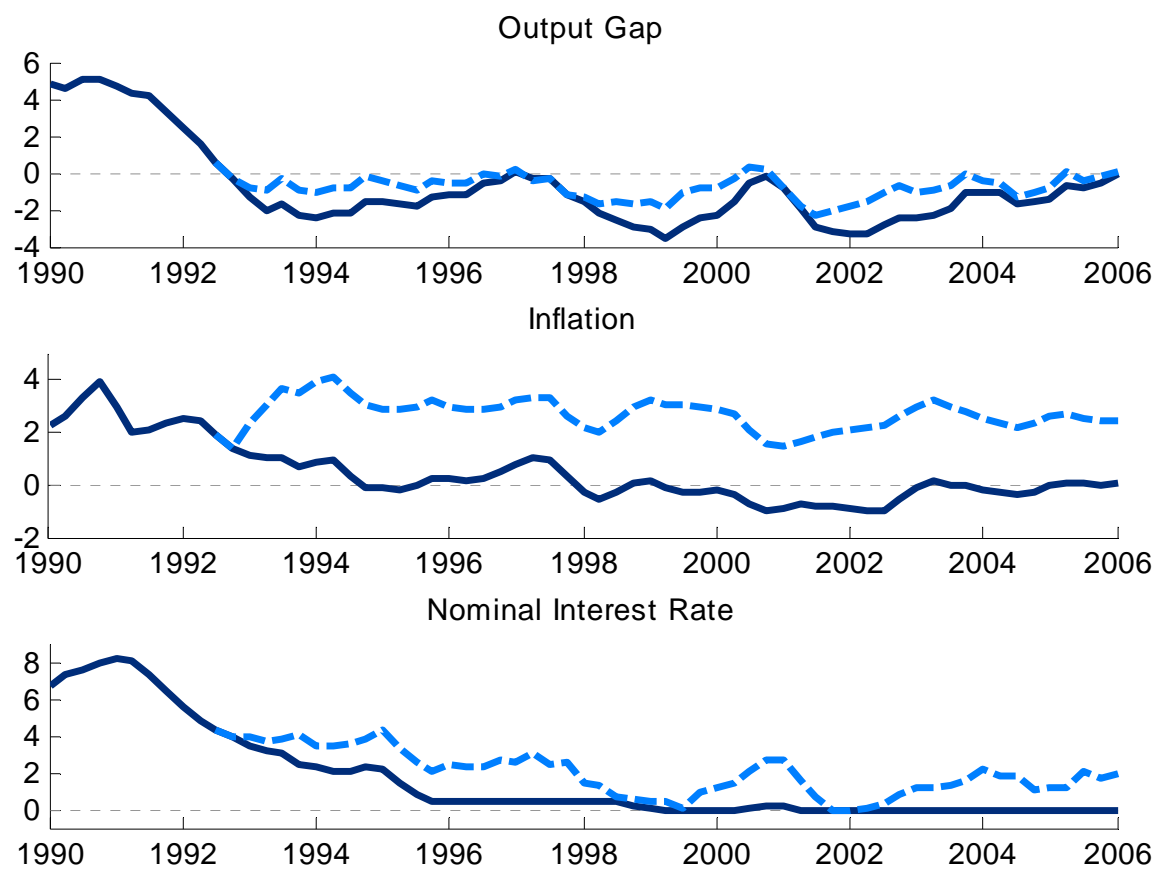

Notes: figure reports actual path (solid line) of output gap, inflation, and interest rates, and simulated counterfacual path (dashes).

\section{Price-Level Targeting}

A number of papers on optimal monetary policy in a low-inflation environment have recommended policy rules that target the price level as opposed to the inflation rate. The rationale for price-level targeting is that any spell of deflation must be followed by an economic expansion with higher inflation that returns the price level to its target. The anticipation of this intensified future inflation reduces real interest rates during the deflationary spell, thus moderating the associated output contraction. Eggertsson and Woodford (2003) found that a price-level targeting rule was optimal in a purely forwardlooking model. ${ }^{37}$ It seems interesting to investigate whether price targeting would have improved macroeconomic performance in Japan based on an estimated with a mix of forward- and backward-looking behavior.

\footnotetext{
${ }^{37}$ Other studies that recommend price-level targeting in a low-inflation environment include Jung, Teranishi, and Watanabe (2005), and Laxton, N'diaye and Pesenti (2006). Adam Posen's (2002) proposal is akin to pricelevel targeting, and is formulated as follows: "Since the price level has been declining for the last five years, we need an equal number of point-years of positive inflation to restore price stability."
} 
In this final counterfactual experiment, the central bank has a target, $p_{t}^{*}$, for the price level, $p_{t}$. The price target is assumed to have a trend with a slope equal to the estimated inflation target, i.e., about one percent per year. ${ }^{38}$ The price target therefore evolves based on the following process:

$p_{t}^{*}=p_{t-1}^{*}+\pi_{t}^{*}$

As before, the central bank is assumed to operate in a forward-looking manner, raising policy rates if the price-level forecast rises above the price target. Therefore, the new interest-rate reaction function can be expressed as follows:

$r_{t}=\max \left\{0, E_{t-1}\left(r_{t}^{*}+\pi_{t}^{*}\right)+\phi_{p} E_{t-1}\left(p_{t+4}-p_{t+4}^{*}\right)+\varepsilon_{t}^{r}\right\}$

The magnitude of the price-level response parameter, $\ell_{p}$, is assumed to be the same as the inflation-response parameter, so that $\phi_{p}=1.7$, implying that an expected 1 percent increase in the price level above the target is associated with a 1.7 percentage-point increase in the policy rate. When the price level is expected to meet its target, the nominal rate equals its neutral rate, equal to the sum of the real natural rate of interest, and the slope of the price trend, $r_{t}^{*}+\pi_{t}^{*}$. For simplicity, I assume that there is no interest-rate smoothing, and no additional explicit output-gap response. ${ }^{39}$

The simulation results suggest that economic performance would have benefited substantially from price-level targeting. As before, the new policy is introduced in 1993Q1 (Figure 10). Following the onset of the contractionary shocks, counterfactual output still falls below potential, but the downturn is relatively shallow, and output returns to potential by 1995. During each of the subsequent contractionary shocks, output rebounds more quickly than under the estimated policy rule. In addition, the actual estimated cumulative output loss is now replaced with a cumulative output gain of 1.4 percent of potential GDP. Regarding inflation performance, the average inflation rate is 1.1 percent per year during the sample

\footnotetext{
${ }^{38}$ Assuming an upward trend applies Friedman's (2003) recommendation regarding the Eggertsson-Woodford price-targeting framework. In particular, Friedman emphasized that "it would be a win-win choice to aim for an upward-sloping price trajectory. Doing so would reduce the likelihood of hitting the zero bound on nominal interest rates, and it would improve the functioning of the real economy away from that bound" (Friedman, 2003, p. 217). Indeed, repeating the simulation while assuming no price-level trend (with $\pi_{t}^{*}=0$ ) reduces the improvement in output relative to the actual data, and reduces the average inflation rate to zero.

${ }^{39}$ The specification of price-level targeting used here is similar to that used by Laxton, N'diaye, and Pesenti (2006). The results are very similar when the policy rule in equation (9) is augmented to include interest-rate smoothing, and when an output-response coefficient $\left(\phi_{x}\right)$ equal to the estimated value of 0.09 is introduced.
} 
period, broadly in line with the targeted price trend. To achieve these results despite the adverse shocks that arrive throughout the simulation sample, the policy interest is held at zero for all but two quarters during 1995Q2-2006Q1.

This final counterfactual simulation therefore yields an interesting result: price-targeting would have delivered more stable macroeconomic performance than a higher inflation target and more vigorous output-gap response combined. This finding therefore contributes the growing literature that endorses explicit or implicit price-level targeting. At the same time, however, while price targeting appears to perfom well in the face of the deflationary shocks considered here, it is worth recognizing a possible concern regarding price targeting in times of high inflation. In particular, as Friedman (2003) emphasizes, price-level targeting implies the need for potentially costly monetary policy contractions following one-time increases in the price level. Given this possible concern, this paper leaves a more comprehensive assessment of price-level targeting to future research.

Figure 10. Actual and Counterfactual Macroeconomic Dynamics:

Price Target
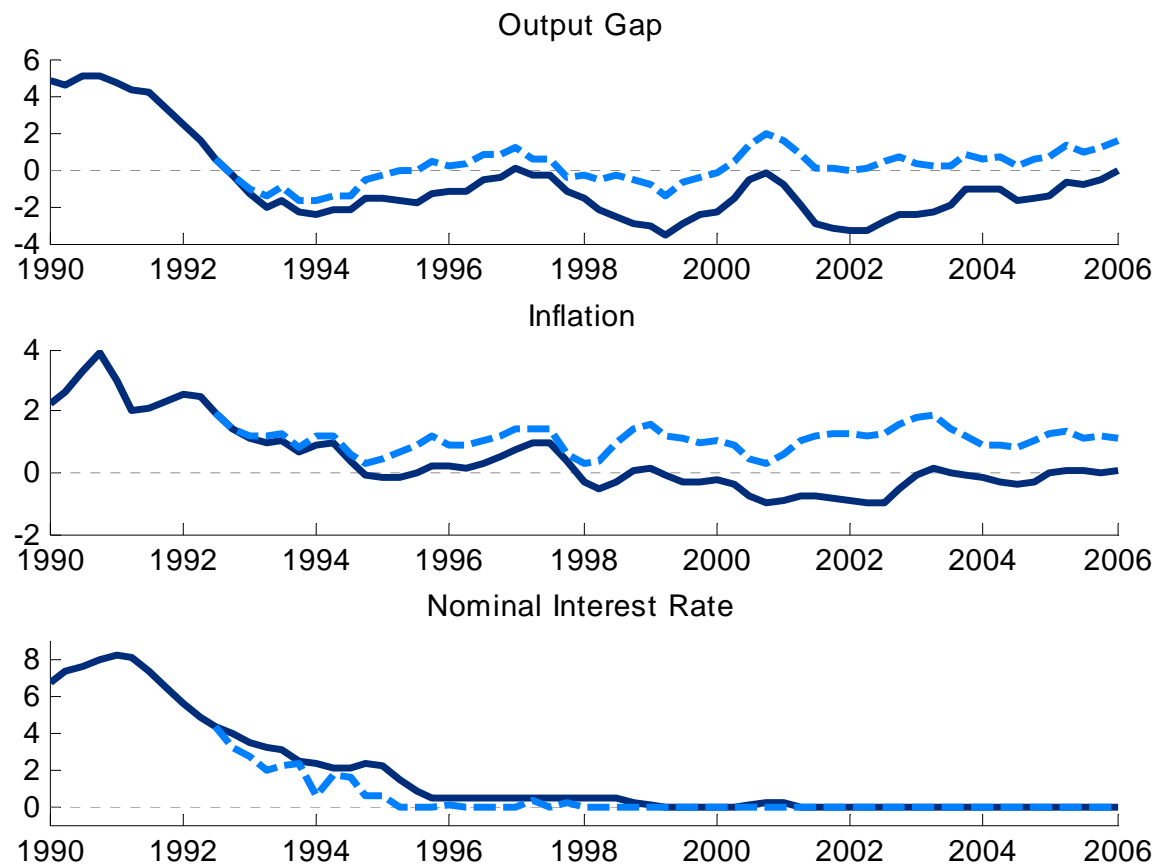

Notes: Figure reports actual path (thick line) of output gap, inflation, and interest rates, and simulated counterfacual path under price-targeting policy rule (dashes). 


\section{Conclusion}

A number of studies blame the Bank of Japan for making exceptional policy errors that precipitated the economy into a liquidity trap, and ushered in a "Lost Decade." My analysis suggests that the Bank of Japan's interest rate policy fits a forward-looking reaction function with an inflation target that declined over time, reaching about 1 percent in the early 1990s. These results suggest that there was nothing unorthodox about Japanese interest-rate policy.

Next, using an estimated structural model, I identify a number of adverse shocks occurring over the 1990s. It thus follows that monetary policy was not solely responsible for the economy’s poor performance. However, the Bank’s policy rule had an Achilles' heel. Aiming for a low inflation level and responding to the economy according to a conventional policy rule provided insufficient insurance against the contractionary shocks that occurred over the 1990s.

The counterfactual simulations based on the series of estimated shocks that occurred over the 1990s suggest that a rule that combined (i) a higher inflation target of about 4 percent per year and (ii) a more vigorous response to the output gap would have substantially improved the economy's performance and would have avoided the zero bound on nominal interest rates. Importantly, rules that had only (i) or (ii) would have provided only partial protection against the large deflationary shocks. I also find that a price-level target would have delivered superior stabilization results.

So what lessons does Japan's experience offer for the rest of the world? Following the most severe financial crisis since the Great Depression, and the deepest recession since the Second World War, how can monetary policy help to avoid a new "Lost Decade?” A number of central banks still regard an interest-rate policy that aims for very low inflation, such as 0-2 percent, with all other macroeconomic objectives being secondary..$^{40}$ Some of these central banks operate in economies that have similar structures to the Japanese economy and have, during the recent crisis, been subject to similar shocks. The results in this paper suggest that such economies may need to take out greater insurance against such shocks by raising their inflation targets and increasing their efforts to stabilize output, or by adopting a form of price-level targeting.

\footnotetext{
${ }^{40}$ As Ball (2000) notes, "For many central banks, including the ECB, price stability is not just an objective of policy, it is the objective" (Ball, 2000, p. 203).
} 


\section{References}

Ahearne, Alan, Joseph Gagnon, Jane Haltmaier, and Steve Kamin, and Christopher Erceg, Jon Faust, Luca Guerrieri, Carter Hemphill, Linda Kole, Jennifer Roush, John Rogers, Nathan Sheets and Jonathan Wright, 2002, "Preventing Deflation: Lessons from Japan’s Experience in the 1990s,” International Finance Discussion Papers, Board of Governors of the Federal Reserve System.

Baba, Naohiko, Motoharu Nakashima, Yosuke Shigemi, Kazuo Ueda, and Hiroshi Ugai, 2005, "Japan's Deflation, Problems in the Financial System, and Monetary Policy," Monetary and Economic Studies 23(1), pp. 47-111.

Ball, Laurence, 2000, Policy Panel on “Why Price Stability?” at the First ECB Central Banking Conference in Frankfurt am Main, November 2000.

Bank of Japan, 2009, “Outlook for Economic Activity and Prices,” May 2009, http://www.boj.or.jp/en/type/release/teiki/tenbo/gor0904b.pdf

Ball, Laurence, 2000, Policy Panel on Why Price Stability? at the First ECB Central Banking Conference in Frankfurt am Main, November 2000.

Bernanke, Ben S., and Mark Gertler, 1999, "Monetary Policy and Asset Price Volatility,” in 1999 Symposium: New Challenges for Monetary Policy, pp. 77-128, Kansas City: Federal Reserve Bank of Kansas City.

Bernanke, Ben S., 2000, “Japanese Monetary Policy: A Case of Self-Induced Paralysis?” in Ryoichi Mikitani and Adam S. Posen (eds.), Japan's Financial Crisis and its Parallels to U.S. Experience, Special Report 13 (September 2000), Washington, DC: Institute for International Economics.

Blanchard, Olivier, 2000, "Bubbles, Liquidity Traps, and Monetary Policy,” in Ryoichi Mikitani and Adam S. Posen (eds.), Japan's Financial Crisis and its Parallels to U.S. Experience, Special Report 13 (September 2000), Washington, DC: Institute for International Economics.

Blanchard, Olivier, 2003, Macroeconomics, Third Edition, Prentice-Hall.

Boivin, Jean and Marc P. Giannoni, 2006, “Has Monetary Policy Become More Effective?,” The Review of Economics and Statistics, August 2006, 88(3): pp. 445-462. 
Clarida, R., J. Gali and M. Gertler, 1997, "Monetary Policy Rules in Practice: Some International Evidence,” European Economic Review, Vol. 42 (1998), pp. 10331067.

Curdia, Vasco, and Michael Woodford, 2008, “Credit Frictions and Optimal Monetary Policy,” mimeo, Princeton University.

Duisenberg, Wim, 2003, Remarks at Press Seminar on the Evaluation of the ECB's Monetary Policy Strategy, http://www.ecb.int/press/pressconf/2003/html/is030508 1.en.html

Eggertsson, Gauti, and Michael Woodford, 2003, "Optimal Monetary Policy in a Liquidity Trap,” Brookings Papers on Economic Activity 1:2003.

Eggertsson, Gauti, 2006a, “Was the New Deal Contractionary?” Federal Reserve Bank of New York Staff Report No. 264, October 2006.

Eggertsson, Gauti B., 2006b, “The Deflation Bias and Committing to Being Irresponsible,” Journal of Money, Credit and Banking, Vol. 38, No. 2 (Mar., 2006), pp. 283-321

Eggertsson, Gauti, 2008, “Great Expectations and the End of the Depression,” American Economic Review, 2008: 90(4).

Feldstein, Martin, 1996, “Overview,” in Federal Reserve Bank of Kansas City, 1996, Achieving Price Stability.

Friedman, Benjamin M., 2003, “Comments and Discussion,” Brookings Papers on Economic Activity 1:2003.

Gertler, Mark, “Comments and Discussion,” Brookings Papers on Economic Activity $1: 2003$.

Hara, Naoko, Naohisa Hirakata, Yusuke Inomata, Satoshi Ito, Takuji Kawamoto, Takushi Kurozumi, Makoto Minegishi, and Izumi Takagawa, 2006, "The New Estimates of Output Gap and Potential Growth Rate,” Bank of Japan Review 2006-E-3.

Hayashi, Fumio and Edward C. Prescott, 2002, “The 1990s in Japan: A Lost Decade,” Review of Economic Dynamics, Vol. 5, pp. 206-235.

Hunt, Benjamin L., and Douglas M. Laxton, 2003, “The Zero-Interest-Rate Floor and Its Implications for Monetary Policy in Japan,” in Tim Callen and Jonathan D. Ostry 
(eds.), 2003, Japan's Lost Decade: Policies for Economic Revival (International Monetary Fund, 2003).

International Monetary Fund, 2009, World Economic Outlook, April 2009, Washington, DC: International Monetary Fund.

Iwamara, Mitsuru, Takeshi Kudo, Tsutomu Watanabe, 2006, "Monetary and Fiscal Policy in a Liquidity Trap: The Japanese Experience 1999-2004,” in Ito, Takatoshi and Andrew K. Rose (eds.), 2006, Monetary Policy with Very Low Inflation in the Pacific Rim, NBER-East Asia Seminar on Economics, Vol. 15. Chicago and London: University of Chicago Press, 2006.

Jung, Taehun, Yuki Teranishi, and Tsutomu Watanabe, 2005, “Optimal Monetary Policy at the Zero-Interest-Rate Bound,” Journal of Money, Credit and Banking, Vol. 37(5), pp. 813-35.

Kahn, George A., 1996, “Achieving Price Stability: a Summary of the Bank's 1996 Symposium,” Economic Review, Fourth Quarter 1996, Federal Reserve Bank of Kansas City.

Krugman, Paul, 1998, “It’s Baaack! Japan’s Slump and the return of the Liquidity Trap,” Brookings Papers on Economic Activity 2:1998.

Kuttner, Kenneth N., and Adam S. Posen, 2002, "Fiscal Policy Effectiveness in Japan,” Journal of the Japanese and International Economies, Volume 16, Issue 4, December 2002, pp. 536-558.

Kuzin, Vladimir, 2006, “The Inflation Aversion of the Bundesbank: a State Space Approach, Journal of Economic Dynamics and Control, 30 (2006), pp. 1671-1686.

Laubach, Thomas and John C. Williams, 2003, "Measuring the Natural Rate of Interest," Review of Economics and Statistics, Vol. 85 (2003), pp. 1063-1070.

Laxton, Douglas, Papa N'Diaye, and Paolo Pesenti, 2006, "Deflationary Shocks and Monetary Rules: An Open-Economy Scenario Analysis ,” Journal of the Japanese and International Economies, Vol. 20, Issue 4 (2006).

Leigh, Daniel, 2008, “Estimating the Federal Reserve’s Implicit Inflation Target: A State Space Approach,” Journal of Economic Dynamics and Control, 32 (2008), pp. 20132030. 
Ogaki, Masao, and Carmen M. Reinhart, 1998, “Measuring Intertemporal Substitution: The Role of Durable Goods,” Journal of Political Economy, 106, 1078-98.

Okina, Kunio, and Shigneori Shiratsuka, 2004, "Policy Commitment and Expectation Formation: Japan's Experience Under Zero Interest Rates,” North American Journal of Economics and Finance 15(1) (March), pp. 75-100.

Okubo, Masakatsu, 2008, "On the Intertemporal Elasticity of Substitution under Nonhomothetic Utility,” Journal of Money, Credit and Banking, Vol. 40, No. 5 (August 2008).

Posen, Adam S., 2000, “The Political Economy of Deflationary Monetary Policy,” in Ryoichi Mikitani and Adam S. Posen (eds.), Japan's Financial Crisis and its Parallels to U.S. Experience, Special Report 13 (September 2000), Washington, DC: Institute for International Economics.

Posen, Adam S., 2002, “Deflation and the Bank of Japan,” Op-ed from The Japan Times, September 23, 2002.

Rabanal, Pau, and Juan F. Rubio-Ramirez, 2005, “Comparing New Keynesian models of the business cycle: A Bayesian approach,” Journal of Monetary Economics, Vol. 52(6), pp. 1151-1166.

Reifschneider, David, and John C. Williams, 2000, “Three Lessons for Monetary Policy in a Low-Inflation Era,” Journal of Money Credit and Banking, Vol. 32, No. 4, pp. 936964.

Shinotsuka, Eiko, 2000, Speech to the Japan Society of Monetary Economics on May 27, 2000, Bank of Japan Speeches and Statements.

Shiratsuka, Shinegori, 1999, "Measurement Error in Japanese Consumer Price Index,” Federal Reserve Bank of Chicago, Working Paper No. WP/99/2.

Sims, Christopher A., 2002, “Solving Linear Rational Expectations Models,” Computational Economics, Vol. 20(1-2), pp. 1-20.

Smets, Frank, and Rafael Wouters, 2007, "Shocks and Frictions in US Business Cycles: A Bayesian DSGE Approach." American Economic Review, 97(3): 586-606.

Sugo, Tomohiro, and Kozo Ueda, 2008, "Estimating a Dynamic Stochastic General Equilibrium Model for Japan,” Journal of the Japanese and International Economies, Vol. 22(4), pp. 476-502. 
Taylor, John B., 1993, “Discretion Versus Policy Rules in Practice,” Carnegie-Rochester Series on Public Policy 39, 195-214.

Woodford, Michael, 2003, Interest and Prices: Foundations of a Theory of Monetary Policy, Princeton University Press.

Yamaguchi, Yukata, 2000, “Thinking behind Current Monetary Policy,” Remarks at the Japan National Press Club (4 August). 


\section{Appendix}

This appendix explains how the simulations impose the zero interest-rate floor. To impose the non-negativity constraint on the model, I use the procedure of Reifschneider and Williams (2000). This procedure assumes that the zero lower bound implies non-negative shocks to the nominal interest rate reaction function. In particular, the linear model described by equations (1)-(7) is augmented with anticipated shocks to the policy interest rate in the current period and $N$ future periods. These disturbances equal zero if the unconstrained policy-interest rates rule implies a positive rate, and the absolute value of the unconstrained rule if the rule implies a negative interest rate. The nominal interest rate therefore respects the zero interest rate floor for the current and $N$ future periods. This assumption is consistent with the notion that fiscal policy could eventually be expected to provide the necessary stimulus to prevent an unstable deflationary spiral. The simulations are based on $N=12$, but the results are not sensitive to the exact value of $N$. 